\title{
Influence of a supervised antenatal exercise program on estimates of heart rate responsiveness
}

\author{
Rhiannon Carpenter, Michael J Lewis
}

\section{ABSTRACT}

Aims: This study examined the influence of a supervised antenatal exercise program on heart rate function in pregnant women. Methods: Participants were randomly assigned to an Exercise group (weekly physical exercise) or a Control group. Physiological assessments were carried out during mid- and late pregnancy and three months following birth. Heart rate variability (HRV) provided estimates of cardiac sympathetic and parasympathetic control, and phase-rectified signal averaging (PRSA) provided estimates of cardiac acceleration (AC) and deceleration (DC) capacities. The testing protocol included a range of physical states designed to provoke autonomically mediated changes in heart rate. Relationships between cardiac variables and participants' ages and body mass indices (BMIs) were also assessed. Results: Heart rate variability indices were similarly reduced during late pregnancy in both groups of women, with the exception of the normalized high frequency index (HFn). High frequency index was significantly lower for "exercisers" during late pregnancy, suggesting a greater shift toward sympathetic dominance. Exercisers also had greater reductions in $\mathrm{AC} / \mathrm{DC}$ during late pregnancy, indicating reductions in heart rate responsiveness. Early-pregnancy BMI was a predictor of $\mathrm{HF}, \mathrm{AC}$, and $\mathrm{DC}$ during late pregnancy in Controls but not in Exercisers. Conclusion: This study has extended our understanding of

Rhiannon Carpenter ${ }^{1}$, Michael J Lewis ${ }^{1}$

Affiliations: 'School of Sport and Exercise Sciences, Swansea University, Swansea, UK.

Corresponding Author: Michael J Lewis, School of Sport and Exercise Sciences, Swansea University, Swansea, UK; Email: m.j.lewis@Swansea.ac.uk

Received: 20 July 2019

Accepted: 04 September 2019

Published: 23 October 2019 the influence of antenatal exercise on heart rate responsiveness. Women who exercised regularly had the lowest values for $\mathrm{AC} / \mathrm{DC}$ during late pregnancy, and we speculate that this might reflect a positive influence of exercise on uterine arterial impedance.

Keywords: Autonomic nervous system, Heart rate variability, Physical activity, Pregnancy

\section{How to cite this article}

Carpenter R, Lewis MJ. Influence of a supervised antenatal exercise program on estimates of heart rate responsiveness. Edorium J Matern Child Health 2019;4:100007Mo1RC2019.

Article ID: 100007Mo1RC2019

$* * * * * * * * *$

doi:10.5348/100007Mo1RC2019RA

\section{INTRODUCTION}

There is general consensus that being physically active during pregnancy has no harmful effects for women or their fetuses if the exercise sessions are supervised and individually prescribed [1-4]. The recent Canadian guidelines on physical activity throughout pregnancy [5] recommend that pregnant women (without contraindication for exercise) should accumulate at least 150 minutes of moderate-intensity physical activity each week (over a minimum of three days per week) to achieve clinically meaningful reductions in pregnancy complications (including hypertensive disorders, gestational diabetes, and excessive weight gain). Furthermore, a recent meta-analysis found that antenatal physical activity is associated with better neonatal outcomes, including a 39\% reduction in the likelihood of macrosomia [6]. 


\section{EDORiUM Journals}

Edorium J Matern Child Health 2019;4:100007M01RC2019.

www.ejmaternalchildhealth.com

Carpenter et al. 2

We might expect that antenatal exercise would also be associated with alterations in maternal physiology, including adaptations to exercise (e.g., the heart's ability to dynamically respond to fluctuations in metabolic demand). One way to determine cardiac responsiveness is to measure the variation in beat-tobeat duration of the cardiac cycle (HRV). Heart rate variability has been widely used to estimate autonomic nervous system (ANS) influences on heart rate in various populations [7]. Previous studies by our group have confirmed that in the second trimester "normal" pregnancy is associated with diminished HRV (sympathetic and parasympathetic autonomic activity) [8], with a further reduction in parasympathetic activity during the third trimester [9]. We also found that pregnant women who exercised regularly had lower levels of cardiac autonomic activity than those who did not [9]. However, it is recommended that HRV should be calculated only during steady-state conditions. Heart rate variability is therefore of questionable utility when we wish to characterize an individual's cardiac responses to activities of daily living, during which transient perturbations in metabolic demand are common and technical artifacts or noise in recordings is more likely. An alternative measure of an individual's heart rate "responsiveness" that avoids these restrictions and uses the PRSA technique [10]. Phaserectified signal averaging identifies quasi-periodicities in a time signal that would normally be masked by nonstationarities, noise, and artifacts. Phase-rectified signal averaging can be used to reconstruct an RR data set into two averaged RR time series that separately characterize the so-called cardiac AC and cardiac DC. Phase-rectified signal averaging provides a robust estimate of cardiac autonomic regulation that reflects an integrated response across a range of physiological states [11]. The magnitudes of PRSA-derived AC and DC are reduced with age in both health and disease [12-14] and are greatest in young individuals with high aerobic fitness [15]. Casati et al. [16] have carried out the only study to date using PRSA-derived measures of cardiac function in pregnant women, reporting higher DC values for women with hypertensive disorders of pregnancy and for those with intrauterine growth restricted pregnancies.

The main aim of this study was to examine the influence of regular antenatal exercise on measures of heart rate function in pregnant women. Specifically, we sought (1) to compare HRV, AC, and DC in women who had attended an antenatal exercise program with those who had not, and (2) to determine whether changes in these variables during pregnancy are related to participants' ages and BMIs, and whether any such relationships are influenced by antenatal exercise.

\section{MATERIALS AND METHODS}

\section{Participants}

Ethical approval was obtained from the South West Wales Research Ethics Committee of the Abertawe Bro Morgannwg University NHS Health Board (12/ WA/o081). The trial was registered at ClinicalTrials. gov (trial identifier NCT02503995). Eligible participants were apparently healthy pregnant women aged 18 years or over, with no existing complications of pregnancy at their 12-week dating scan. Potential participants were approached via direct contact at the antenatal clinic (during the 12-week dating scan appointment). Exclusion criteria were: a history of cardiovascular or chronic respiratory problems, sleep apnea, or central/peripheral nervous system disorder. Eligible participants were provided with details about the study, including practical requirements and potential risks, and were given one week to consider whether they wished to take part. Individuals who wished to participate gave their written consent. All procedures were conducted in accordance with the Declaration of Helsinki.

\section{Study design}

Participants were randomly assigned to either an Exercise group (members of which participated in a weekly physical exercise program) or a Control group (who did not participate in the program but received usual healthcare advice). We used a "flexible" randomization procedure in which participants were asked if they were happy to be randomized into either the Exercise or Control groups: those answering "no" were allocated to their chosen group, while those answering "yes" were assigned to a group using a simple random number generator. Physiological monitoring was carried out between 12 and 16 weeks and between 34 and 36 weeks gestational age, and also three months following birth. During each assessment participants undertook a series of physical maneuvers designed to provoke changes in the cardiovascular and autonomic nervous systems.

\section{Exercise programs}

Participants assigned to the exercise group attended weekly exercise classes from the 20th week of pregnancy until full-term or until they felt they could no longer undertake physical activity. All classes were led or supervised by a qualified midwife, and participants' heart rates were monitored throughout using heart rate monitors (Polar FT1 Heart Rate Monitor, Polar Electro, Finland) and the BORG "rating of perceived exertion" 


\section{EDORiUM Journals}

Edorium J Matern Child Health 2019;4:100007M01RC2019.

www.ejmaternalchildhealth.com

Carpenter et al. 3

scale [17]. Classes consisted of 18 minutes of recumbent cycling, 10 minutes of stretching and toning exercises, and 15 minutes of pelvic floor exercises. The recumbent cycling exercise (V-Fit BST-RC, Beny Sports Ltd., UK) consisted of a three-minute warm-up (with no resistance) followed by 15 minutes of continuous cycling. Exercise workload was increased by one "level" on the bike every two minutes, until the participant reached the heart rate target zone for antenatal aerobic exercise suggested by the Royal College of Obstetrics and Gynaecology [18].

\section{Physiological assessment}

Participants were asked to refrain from drinking tea, coffee, or alcohol and from eating a heavy meal within two hours prior to assessment and to not exercise within 24 hours prior to assessment. On confirmation of this, participants were asked to: recline $\left(45^{\circ}\right.$ semirecumbent) for six minutes, stand for six minutes, perform light stepping exercise (six minutes), sit and rest (six minutes), perform mental arithmetic calculations (three minutes), breathe synchronously with a metronome (three minutes), and breathe spontaneously (three minutes). This protocol lasted 33 minutes, during which participants underwent continuous Holter electrocardiogram (ECG) monitoring (Pathfinder/Lifecard Digital system; Spacelabs Medical Ltd., UK). Electrocardiogram recordings were analyzed using a Reynolds Pathfinder digital analyzer (Spacelabs Medical Ltd., UK). Beat-to-beat cardiac intervals (RR) were measured automatically and spurious data points (artefacts) were removed manually. RR data were then analyzed as a single 33-minute period using Matlab. Following linear detrending the HRV variables were quantified according to the European Society of Cardiology guidelines [4]: (1) RMSSD (square root of the mean squared differences of successive RR intervals), (2) SDRR (standard deviation of RR intervals), (3) Total Power [the total amount of "power" (variance) in the bandwidth O to $0.4 \mathrm{~Hz}$, (4) VLF (very low frequency power, in the bandwidth 0.003-0.04 Hz), (5) LF (low frequency power in the bandwidth $0.04-0.15 \mathrm{~Hz}$ ), (6) HF (high frequency power in the bandwidth $0.15-0.4 \mathrm{~Hz}$ ), (7) HFn (normalized high frequency power): $\mathrm{HFn}=\mathrm{HF} /$ (Total Power - VLF).

We used the PRSA procedure [8] to quantify the AC and DC for the same 33-minute RR time series: (1) multiple $\mathrm{DC}$ and $\mathrm{AC}$ "anchor points" were identified, respectively, as those RR intervals longer than or shorter than the preceding RR interval; (2) a truncated RR time series was defined around each of the anchor points (a 61-point series, including 30 points preceding and following the anchor point); (3) the truncated RR time series were aligned (separately for $\mathrm{DC}$ and $\mathrm{AC}$ anchor points) and averaged to form the PRSA time series; (4) DC and AC were calculated as $\left[\left(X_{0}+X_{1}\right)-\left(X_{-1}+X_{-2}\right)\right] / 4$, where $X_{\mathrm{o}}$ and $X_{1}$ are the averaged RR intervals at the anchor point and the immediately following point, and $X_{-1}$ and $X_{-2}$ are the two averaged RR intervals immediately preceding the anchor point.

\section{Statistical analysis}

Matlab (version 2017b, The Mathworks, Cambridge, UK) was used to perform statistical analysis. Onesample Kolomogorov-Smirnov tests showed that none of the quantified variables were normally distributed. Consequently paired [within-group, early vs. lategestation and late gestation vs. postpartum (PP)] changes were assessed using the Wilcoxon Signed-Rank test; betweengroup differences (Exercisers vs. Controls) were assessed using the Wilcoxon Rank Sum test. Descriptive data are presented as Median (M) and Lower/Upper Quartile (Q1, Q2) values. Spearman's Rho assessed possible monotonic correlations between age/BMI and any cardiac variable for which a between-group difference was observed during late pregnancy. If significant correlations were found then, following visual confirmation of a linear relationship, group-specific regression slopes were compared using the $z$-statistic $\left[z=\left(b_{1}-b_{2}\right) /\left(S_{\mathrm{b}_{1}}{ }^{2}-S_{\mathrm{b}_{2}}{ }^{2}\right)^{1 / 2}\right.$, where $b_{1}$ and $b_{2}$ are the slopes of the two regression lines and $S_{\mathrm{b} 1}, S_{\mathrm{b} 2}$ are the standard errors of the slopes. To control for Type I errors associated with multiple statistical comparisons, the level of statistical significance for paired comparisons (between- and within-group) and for correlations among the measured variables was established using the Bonferroni correction $\left(\alpha_{\text {per variable }}=0.05 / \mathrm{m}\right.$, where $m$ is the number of comparisons) as follows: (i) for the family of eight HRV indices, $\alpha_{\text {per variable }}=0.05 / 8=0.006$, (ii) for the PRSA-derived indices (AC and DC), $\alpha_{\text {per variable }}=0.05 / 2$ $=0.025$, and (iii) for the correlation analysis $\alpha_{\text {per variable }}$ $=0.05 / n$ (where $n$ is the number of variables for which correlations were tested-limited to those variables for which there was a significant between-group difference during late pregnancy).

\section{RESULTS}

Ninety-seven women were recruited and randomized into Exercise and Control groups (Figure 1). Sixty-six women (68\% participant retention) attended both of the antenatal assessments ("Mid" and "Late" pregnancy), 24 of whom were from the Exercise group and 42 from the Control group. Eighteen women from the Exercise group and 33 from the Control group also completed the PP assessment (53\% participant retention). A summary of participant characteristics is presented in Table 1 . Statistical comparison showed that the two groups did not differ in age $(\mathrm{p}=0.54)$ or BMI $(\mathrm{p}=0.16)$ at initial assessment (although more Controls were in the "healthy weight" category). There were no appreciable differences in pregnancy outcomes for the two groups (Table 2). 


\section{EDORiUM Journals}

Edorium J Matern Child Health 2019;4:100007M01RC2019.

www.ejmaternalchildhealth.com

None of the cardiac indices differed between exercisers and controls at initial assessment. Figure 2 shows the relative changes in each variable during pregnancy for Exercisers and Controls. Table 3 shows the values of the calculated cardiac variables for Exercise and Control groups during mid- and late pregnancy, together with statistical assessments of antenatal (mid vs. late) changes for each group, and between-group comparisons of variables during late pregnancy.

The primary outcome measures of this study were the late pregnancy values of the cardiac variables. Table 3 shows that four of the HRV variables (HR, RMSSD, SDRR, and HF) changed significantly in Exercisers during pregnancy $(\mathrm{p}=0.002-0.004)$ but only two (HR and RMSSD) were altered in Controls $(\mathrm{p}=0.0001-$ o.002). Acceleration capacity and DC were significantly reduced during late pregnancy in Exercisers $(p=0.0005$ for AC, $p=0.001$ for DC) and in Controls ( $p=0.001$ for $\mathrm{AC}$ and DC). Late pregnancy HFn was lower in Exercisers than in Controls $(\mathrm{p}=0.005)$ and late pregnancy $\mathrm{AC}$ and $\mathrm{DC}$ were both lower in Exercisers $(\mathrm{p}=0.016$ for AC, $\mathrm{p}=$ 0.022 for DC).

Correlation analysis was performed between these three variables (HFn, AC, and DC) and (i) participant age and (ii) BMI (at the point of recruitment into the study). We applied a Bonferroni corrected significance

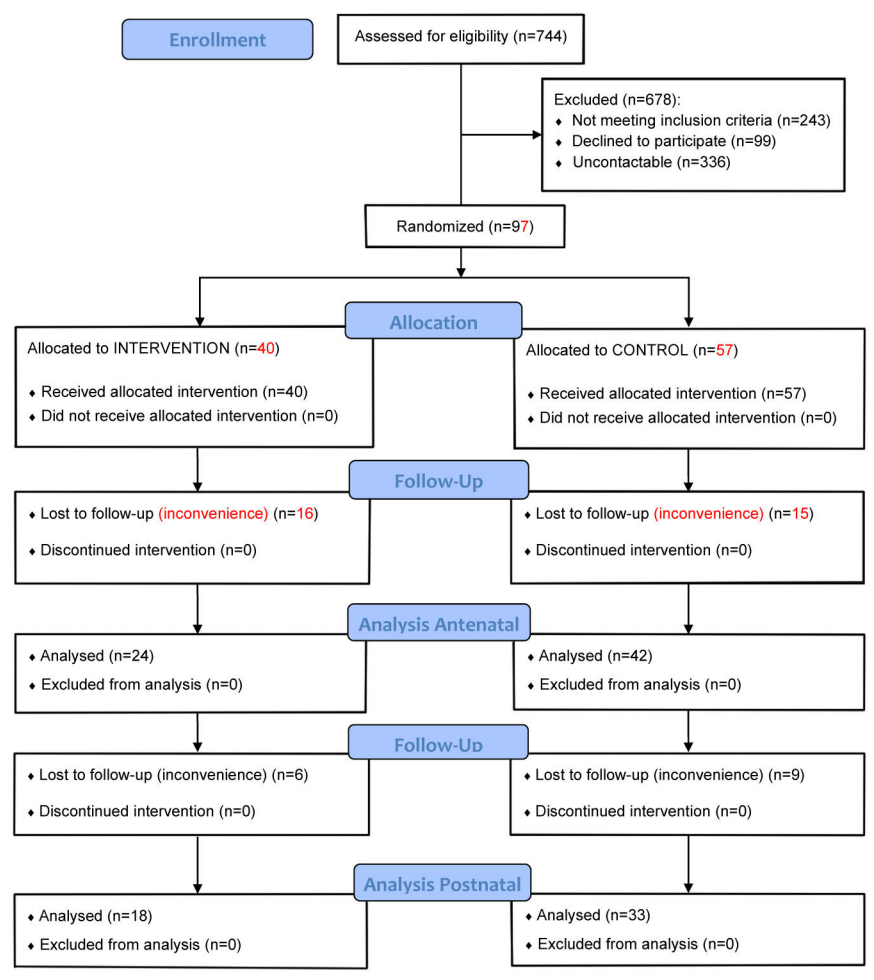

Figure 1: Consort flow diagram for the study.

Table 1: Participant characteristics

\begin{tabular}{|c|c|c|c|c|c|c|}
\hline & & & \multicolumn{2}{|c|}{ Participants, antenatal stage } & \multicolumn{2}{|c|}{ Participants, postnatal stage } \\
\hline & & & $\begin{array}{l}\text { Exercise } \\
(n=24)\end{array}$ & $\begin{array}{l}\text { Controls } \\
(n=42)\end{array}$ & $\begin{array}{l}\text { Exercise } \\
(n=18)\end{array}$ & $\begin{array}{l}\text { Controls } \\
(n=33)\end{array}$ \\
\hline \multirow{6}{*}{$\begin{array}{l}\text { AGE (years) } \\
\text { at initial } \\
\text { assessment }\end{array}$} & Mean & & 29.3 & 30.0 & 29.4 & 30.1 \\
\hline & SD & & 5.6 & 5.2 & 6.2 & 4.4 \\
\hline & \multirow{4}{*}{$\begin{array}{l}\text { Range } \\
\text { [number (\%)] }\end{array}$} & $19-24$ & $5(21)$ & $5(12)$ & $3(17)$ & $2(6)$ \\
\hline & & $25-30$ & $12(50)$ & $21(50)$ & $9(50)$ & $19(58)$ \\
\hline & & $31-35$ & $4(16.5)$ & $10(24)$ & $4(22)$ & $9(27)$ \\
\hline & & $36-41$ & $3(12.5)$ & $6(14)$ & $2(11)$ & $3(9)$ \\
\hline \multirow{6}{*}{$\begin{array}{l}\text { BMI }\left(\mathrm{kg} / \mathrm{m}^{2}\right) \\
\text { at initial } \\
\text { assessment }\end{array}$} & Mean & & 26.8 & 24.9 & 27.7 & 24.6 \\
\hline & $\mathrm{SD}$ & & 5.6 & 4.6 & 6.2 & 4.4 \\
\hline & \multirow{4}{*}{$\begin{array}{l}\text { Range } \\
\text { [number (\%)] }\end{array}$} & $<18.5$ & o & o & o & o \\
\hline & & $18.5^{-24.9}$ & $11(46)$ & $27(64)$ & $8(44)$ & $21(64)$ \\
\hline & & $25.0-29.9$ & $5(21)$ & $8(19)$ & $1(6)$ & $5(15)$ \\
\hline & & $>30$ & $8(33)$ & $7(17)$ & $8(44)$ & $6(18)$ \\
\hline \multirow[t]{3}{*}{ Parity } & \multirow{3}{*}{$\begin{array}{l}\text { Range } \\
\text { [number (\%)] }\end{array}$} & Nulliparous & $12(50)$ & $21(50)$ & $8(44)$ & $15(45)$ \\
\hline & & Primip & $10(42)$ & $18(43)$ & $8(44)$ & $15(45)$ \\
\hline & & Multip & $2(8)$ & $3(7)$ & $2(11)$ & $3(9)$ \\
\hline \multirow[t]{2}{*}{ Gravidity } & \multirow{2}{*}{$\begin{array}{l}\text { Range } \\
\text { [number (\%)] }\end{array}$} & Primagravida & $12(50)$ & $21(50)$ & $9(50)$ & $17(50)$ \\
\hline & & Multigravida & $12(50)$ & $21(50)$ & $9(50)$ & $16(50)$ \\
\hline
\end{tabular}




\section{EDORiUM Journals}

Edorium J Matern Child Health 2019;4:100007M01RC2019.

www.ejmaternalchildhealth.com

Carpenter et al. 5

Table 2: Pregnancy outcomes

\begin{tabular}{|c|c|c|c|c|c|c|c|c|}
\hline & \multicolumn{4}{|c|}{ Participants, antenatal stage } & \multicolumn{4}{|c|}{ Participants, postnatal stage } \\
\hline & \multicolumn{2}{|c|}{ Exercise $(n=24)$} & \multicolumn{2}{|c|}{ Controls $(n=42)$} & \multicolumn{2}{|c|}{ Exercise $(n=18)$} & \multicolumn{2}{|c|}{ Controls $(n=33)$} \\
\hline \multicolumn{9}{|l|}{ Birth weight (g) } \\
\hline Median & \multicolumn{2}{|c|}{3605} & \multicolumn{2}{|c|}{3490} & \multicolumn{2}{|c|}{3470} & \multicolumn{2}{|c|}{3500} \\
\hline \multirow[t]{2}{*}{ Range } & \multicolumn{2}{|c|}{$2780-4750$} & \multicolumn{2}{|c|}{$2620-4820$} & \multicolumn{2}{|c|}{$2780-4340$} & \multicolumn{2}{|c|}{$2640-4820$} \\
\hline & $\mathrm{n}$ & $(\%)$ & $\mathrm{n}$ & (\%) & $\mathrm{n}$ & (\%) & $\mathrm{n}$ & (\%) \\
\hline \multicolumn{9}{|c|}{ Gestational age at birth (weeks) } \\
\hline $34-36$ & o & (o) & o & (o) & o & (o) & o & (o) \\
\hline $37-40$ & 11 & $(46)$ & 18 & $(43)$ & 11 & $(61)$ & 16 & $(48)$ \\
\hline$>40$ & 13 & (54) & 24 & $(57)$ & 7 & (39) & 17 & $(52)$ \\
\hline \multicolumn{9}{|c|}{ Method of delivery } \\
\hline Vaginal & 18 & $(75)$ & 36 & $(86)$ & 12 & $(67)$ & 29 & $(88)$ \\
\hline Caesarean section & 6 & $(25)$ & 6 & (14) & 6 & (33) & 4 & (12) \\
\hline \multicolumn{9}{|l|}{ Complications } \\
\hline Breech & 2 & (8) & 2 & (8) & o & (o) & o & (o) \\
\hline Prolonged rupture & 1 & (4) & 1 & (4) & o & (o) & o & (o) \\
\hline Low platelets & o & (o) & 1 & (2) & o & (o) & 1 & (2) \\
\hline
\end{tabular}

Table 3: Cardiac variables for participants during mid- and late pregnancy

\begin{tabular}{|c|c|c|c|c|c|c|c|}
\hline \multirow[t]{3}{*}{$\begin{array}{l}\text { Cardiac } \\
\text { variable }\end{array}$} & \multicolumn{6}{|c|}{$\begin{array}{c}\text { Mid vs. late pregnancy } \\
\text { Median (interquartile range, IQR) }\end{array}$} & \multirow{3}{*}{$\begin{array}{c}\text { Late } \\
\text { pregnancy } \\
\text { E vs. C } \\
\text { p }\end{array}$} \\
\hline & \multicolumn{3}{|c|}{ Controls (C) } & \multicolumn{3}{|c|}{ Exercisers (E) } & \\
\hline & Mid & Late & $\mathbf{p}$ & Mid & Late & $\mathbf{p}$ & \\
\hline HR (bpm) & $88.1(83,98)$ & $95.5(87,102)$ & $<10^{-4}$ & $88.2(80,98)$ & $100.3(93,104)$ & 0.003 & 0.137 \\
\hline RMSSD (ms) & $26.0(18,32)$ & $21.2(14,29)$ & 0.002 & $26.8(19,32)$ & $14.8(11,21)$ & 0.002 & 0.035 \\
\hline SDRR (ms) & $74.9(64,81)$ & $62.5(53,78)$ & 0.009 & $74.4(61,81)$ & $54.2(48,65)$ & 0.004 & 0.057 \\
\hline VLF $\left(\mathrm{ms}^{2}\right)$ & $4.5(3.6,6.2)$ & $4.1(2.9,6.3)$ & 0.052 & $6.1(3.8,6.2)$ & $3.3(2.5,4.9)$ & 0.012 & 0.120 \\
\hline $\mathbf{L F}\left(\mathrm{ms}^{2}\right)$ & $436.5(323,645)$ & $342.1(208,582)$ & 0.047 & $415.8(279,645)$ & $284.1(191,412)$ & 0.026 & 0.168 \\
\hline HF $\left(\mathrm{ms}^{2}\right)$ & $211.7(117,338)$ & $179.7(72,316)$ & 0.077 & $185.1(111,338)$ & $86.0(42,154)$ & 0.002 & 0.013 \\
\hline $\mathbf{T P}\left(\mathrm{ms}^{2}\right)$ & $729.6(544,1072)$ & $635.7(315,924)$ & 0.036 & $721.8(418,1072)$ & $390.8(242,645)$ & 0.008 & 0.067 \\
\hline HFn & $0.29(0.23,0.37)$ & $0.28(0.21,0.36)$ & 0.886 & $0.27(0.24,0.37)$ & $0.20(0.17,0.29)$ & 0.021 & 0.005 \\
\hline $\mathrm{AC}(\mathrm{ms})$ & $-9.3(-7.6,-12.3)$ & $-7.9(-5.6,-10.1)$ & 0.001 & $-8.5(-7.6,-11.8)$ & $-5.9(-4.4,-7.5)$ & $5 \times 10^{-4}$ & 0.016 \\
\hline DC (ms) & $9.5(6.9,11.2)$ & $8.4(5.8,10.7)$ & 0.001 & $8.8(7.1,11.2)$ & $6.3(4.9,8.3)$ & 0.001 & 0.022 \\
\hline
\end{tabular}

level $\left(\alpha_{\text {per variable }}\right)$ of $0.05 / 3=0.017$ for this part of the analysis. Body mass index was significantly (but weakly) correlated with HFn ( $\mathrm{p}=0.01$, rho $\left.=-0.38 ; r^{2}=0.15\right)$, $\mathrm{AC}\left(\mathrm{p}=3.2 \times 10^{-4}\right.$, rho $\left.=0.53 ; r^{2}=0.19\right)$ and DC $(\mathrm{p}=9.1$ $\times 10^{-4}$, rho $\left.=-0.49 ; r^{2}=0.21\right)$ in Controls but was not correlated with any of the variables in Exercisers. Age was not correlated with any of the variables in either group. Statistical comparison showed that there were significant between-group (Exercise vs. Control) differences in the linear regression slopes of $\mathrm{AC}$ and $\mathrm{DC}$ as functions of $\mathrm{BMI}$ (BMI-AC: $Z=-2.46, \mathrm{p}=0.014$; BMI-DC: $Z=2.57, \mathrm{p}=$ 0.010) but not for BMI-HFn $(Z=0.07, \mathrm{p}=0.95)$. Figure
3 shows the relationships between AC/DC and BMI for Exercisers and Controls.

Secondary outcome measures were the postnatal values of each variable, all of which were substantially changed compared with late pregnancy in Controls ( $\mathrm{p}=$ 0.0005-0.005) while all except HFn were substantially altered in Exercisers ( $\mathrm{p}=0.0005-0.005)$. Exercisers and Controls had similar PP values for all variables $(\mathrm{p}=0.18-$ o.95). Figure 4 provides a between-group comparison of the relative changes (PP vs. late pregnancy) for each cardiac variable. 


\section{EDORIUM Journals}

Edorium J Matern Child Health 2019;4:100007M01RC2019.

www.ejmaternalchildhealth.com

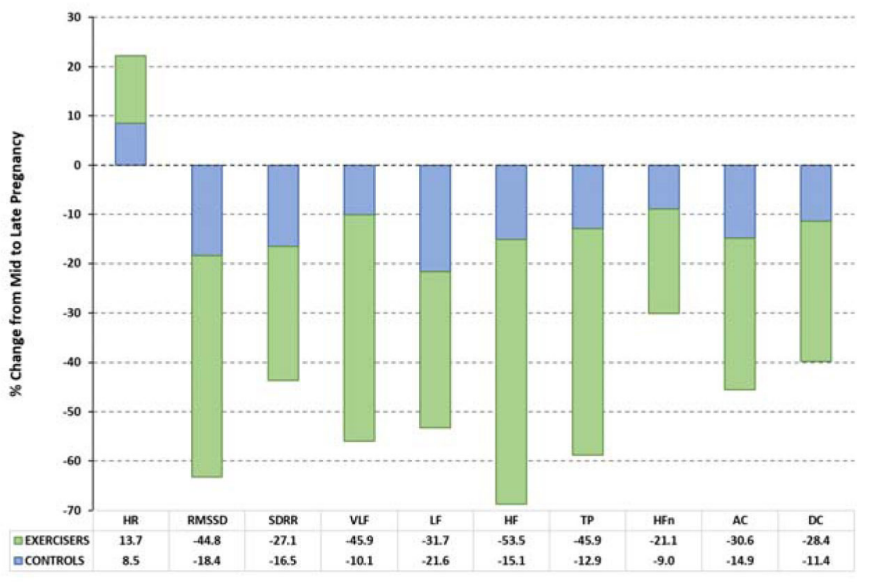

Figure 2: Late vs. mid-pregnancy changes in cardiac variables for Exercisers and Controls.
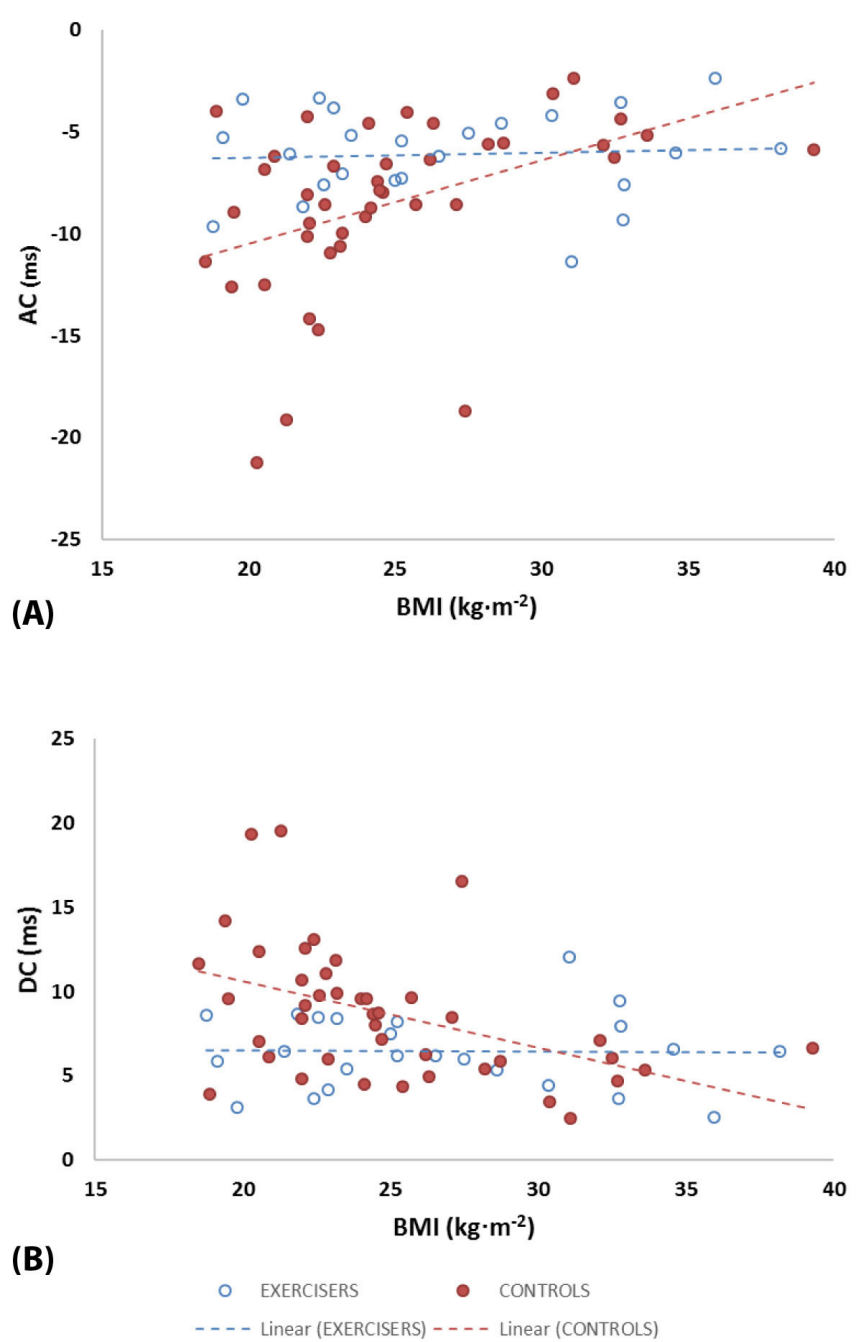

Figure 3: Linear regressions for BMI against (A) AC and (B) DC.

\section{DISCUSSION}

The study provides evidence that a supervised, weekly exercise program influenced heart rate responsiveness



Figure 4: Postpartum vs. late pregnancy changes in cardiac variables for Exercisers and Controls.

during pregnancy: (1) Heart rate variability indices were similarly reduced during late pregnancy in both groups of women, with the exception of the normalized HFn. The reduction in HFn was significantly greater for "exercisers", suggesting a greater shift toward sympathetic dominance; (2) Exercisers had greater reductions in $\mathrm{ACs}$ and $\mathrm{DCs}(\mathrm{AC} / \mathrm{DC}$ reductions were at least twofold greater than in controls). Early-pregnancy $\mathrm{BMI}$ was a predictor of $\mathrm{HF}, \mathrm{AC}$, and $\mathrm{DC}$ during late pregnancy in Controls but not in Exercisers.

Previous studies have shown that regular antenatal physical exercise can significantly alter "normal" maternal cardiovascular and hemodynamic responses, though with some contradictory findings. Carpenter et al. [9] observed that cardiac parasympathetic activity (measured via HRV during the supine resting state) is reduced with advancing gestation, in line with most previous studies [19-21]. However, Carpenter et al. also observed that this reduction in parasympathetic activity was exaggerated (further reduced) in women who participated in antenatal physical exercise [9]. However, other studies have reported that exercise conditioning attenuates the gestational decline in parasympathetic activity [22] and event that it increases it [23]. Driven in part by this lack of clarity, we sought in the present study to quantify HRV during a measurement period that included multiple physical states; albeit that this is an unorthodox approach, we believed that this would be a useful test of the utility of HRV during "real life" activities. Our results showed only limited (but significant) evidence that exercise influenced cardiac parasympathetic function (via diminished late pregnancy HFn). However, PP values of HFn were similar in both groups, so we suggest that antenatal exercise induced an earlier-than-normal shift to cardiac sympathetic dominance.

Our use of an extended, mixed-state analysis period was also advantageous in quantifying the cardiac ACs and DCs introduced by Bauer et al. [10]. Indices of AC and DC can easily be calculated across differing steady- 


\section{EDORiUM Journals}

Edorium J Matern Child Health 2019;4:100007M01RC2019.

www.ejmaternalchildhealth.com

Carpenter et al. 7

state conditions, thereby offering composite estimates of heart rate "responsiveness" during typical daily activities. Calculating HRV, AC, and DC using the same analysis periods allowed a direct comparison of their values and behaviors. We found that both $\mathrm{AC}$ and DC were reduced during late compared with mid-pregnancy, and these reductions were greater in Exercisers. The only previous study to use PRSA-derived indices for evaluating cardiac function in pregnant women was that of Casati et al. [16]. These authors compared DC for women in the $25^{\text {th }}$ to 4oth week of gestation who either had healthy pregnancies, hypertensive disorders of pregnancy (HDP: gestational hypertension alone or in association with features of preeclampsia), or intrauterine growthrestricted pregnancies (IUGR: abdominal circumference $<5$ th centile for gestational age). They reported the lowest DC values for healthy pregnancies $(5.4-8.0 \mathrm{~ms})$ with higher values for women with HDP and IUGR pregnancies. Deceleration capacity increased with the severity of IUGR and the highest values (5.7-9.9 ms) were observed in women with severe IUGR and in those with both IUGR and HDP. Casati et al. observed that women with IUGR+HDP also had higher values for both umbilical artery and uterine artery Doppler pulsatility indices (UmbA-PI and UtA-PI) compared with HDP alone [16]. Deceleration capacity was positively correlated with UtA-PI in pregnancies complicated by either IUGR or HDP, but UmbA-PI was not correlated with DC in either of these conditions.

The study indicates that IUGR influences DC, that this influence is exaggerated by the coexistence of HDP, and that this influence on DC is mediated by physical properties of the uterine artery. Since UtA-PI provides an indirect estimate of vascular impedance (resistance to blood flow) within the fetoplacental circulation [24], Casati et al. [16] suggested that DC might be used as a noninvasive proxy of placental function, with higher DC values suggesting placental impairment. Based on Casati et al.'s premise, our finding that DC was reduced by an additional $17 \%$ from mid- to late pregnancy in Exercisers compared with Controls might be interpreted as reflecting a substantial improvement in fetoplacental blood flow caused by exercise. We note that the highest values recorded for DC by Casati et al. are similar to those of our Control group (5.8-10.7 ms) and higher than in our Exercise group (4.9-8.3 ms). This might be attributable to different measurement protocols in our studies: although the total ECG recording time was similar between the two (33 and 40 minutes), Casati et al. [16] assessed women in a single resting steady state whereas we employed a range of steady states to simulate daily-living activities.

A small number of studies have also quantified DC in the fetus, finding lower values (reduced fetal heart rate responsiveness) in IUGR (i.e., a chronic hypoxic state) compared with healthy controls [25-27]. Stampalija et al. [28] also reported that DC is associated with the middle cerebral artery pulsatility index (which reflects a brain-sparing vascular dilation adaptation to improve blood flow in response to placental insufficiency) in IUGR fetuses from the 25th week of gestation. Thus combined evidence from maternal and fetal studies suggests that a higher-than-expected maternal DC during late pregnancy is indicative of: (i) chronic uterine artery flow restriction, associated with fetal growth restriction, (ii) compensatory dilation of the fetal cerebral artery, and (iii) a resultant blood flow-mediated reduction in fetal DC. If correct, it is remarkable that uterine artery impedance can measurably influence DC in the maternal and fetal heart. The specific mechanism of action of this response is of course something that requires further investigation, complicated by the fact that $\mathrm{DC}$ reflects the overall DC of sinus rhythm across a range of timescales (reflecting a range of vagally modulated influences from multiple physiological process).

We also wanted to determine whether women's ages and BMIs (measured during early pregnancy, assumed to reflecting their prepregnancy weight-related health status) were significant factors in determining their heart rate responsiveness during late pregnancy. Similar to Casati et al. [16] we found that DC was not significantly correlated to gestational age. However, we additionally observed significant inverse-linear relationships between $\mathrm{BMI}$ and late pregnancy HFn, AC, and DC in the Control group, such that each of these cardiac variables was lower in women with higher BMIs. These relationships were absent in Exercisers, suggesting that antenatal exercise had altered the impact of BMI on cardiac responsiveness.

\section{LIMITATIONS}

Our antenatal exercise intervention provided a weekly duration of physical activity lower than currently advised. The recently published Canadian guidelines recommend that pregnant women (without contraindication for exercise) should accumulate at least 150 minutes of moderate-intensity physical activity each week (over a minimum of three days per week). However, two points are worthy of note here: (i) This is the level of physical activity recommended specifically to achieve "clinically meaningful reductions in pregnancy complications." The primary outcome of interest in our study is a measurable influence of physical activity on late pregnancy cardiac (heart rate) function, which we suggest can be achieved with a lower weekly amount of physical activity; (ii) We took a pragmatic approach to our intervention, arguing that more women will engage in regular physical activity if it is manageable-thus making our choice of intervention more realistic for a larger proportion of pregnant women. We did not assess our participants' physical fitness levels as the method of choice for this would have been a maximal oxygen uptake test, which would not have been appropriate or acceptable in this population. We also took a pragmatic approach to participant recruitment: we

Edorium Journal of Maternal and Child Health, Vol. 4; 2019. 


\section{EDORIUM Journals}

did not perform an a priori calculation of sample size but instead aimed to recruit as many participants as possible (which was helped by allowing participants some choice of group membership).

\section{CONCLUSION}

This study has extended our understanding of changes in heart rate responsiveness during pregnancy and of the influence thereon of antenatal physical exercise. Women who exercised regularly during pregnancy had the lowest values for cardiac acceleration and deceleration indices during late pregnancy, and showed an early shift to sympathetic autonomic dominance. We interpret these findings as a beneficial influence of antenatal exercise. Although speculative, this might reflect a positive influence of antenatal exercise on uterine arterial impedance and thus on fetal developmental health.

\section{REFERENCES}

1. RuizJR, Perales M, Pelaez M, Lopez C, Lucia A, Barakat R. Supervised exercise-based intervention to prevent excessive gestational weight gain: A randomized controlled trial. Mayo Clin Proc 2013;88(12):138897.

2. Barakat R, Pelaez M, Cordero Y, et al. Exercise during pregnancy protects against hypertension and macrosomia: Randomized clinical trial. Am J Obstet Gynecol 2016;214(5):649.e1-8.

3. Roldán, O, Perales M, Mateos S, Barakat R. Supervised physical activity during pregnancy improves fetal cardiac response. Rev Int Med Cienc Act Fis Deporte 2015;15(60):757-72.

4. Mottola MF, Artal R. Fetal and maternal metabolic responses to exercise during pregnancy. Early Hum Dev 2016;94:33-41.

5. Mottola MF, Davenport MH, Ruchat SM, et al. No. 367-2019 Canadian guideline for physical activity throughout pregnancy. J Obstet Gynaecol Can 2018;40(11):1528-37.

6. Davenport MH, Meah VL, Ruchat SM, et al. Impact of prenatal exercise on neonatal and childhood outcomes: A systematic review and meta-analysis. $\mathrm{Br}$ J Sports Med 2018;52(21)1386-96.

7. Heart rate variability. Standards of measurement, physiological interpretation, and clinical use. Task Force of the European Society of Cardiology and the North American Society of Pacing and Electrophysiology. Eur Heart J 1996;17(3):354-81.

8. Carpenter RE, D'Silva LA, Emery SJ, Uzun O, Rassi $\mathrm{D}$, Lewis MJ. Changes in heart rate variability and QT variability during the first trimester of pregnancy. Physiol Meas 2015;36(3):531-45.

9. Carpenter RE, Emery SJ, Uzun O, Rassi D, Lewis MJ. Influence of antenatal physical exercise on heart rate variability and QT variability. J Matern Fetal Neonatal Med 2017;30(1):79-84.
10. Bauer A, Kantelhardt JW, Bunde A, et al. Phaserectified signal averaging detects quasi-periodicities in non-stationary data. Physica A: Statistical Mechanics and its Applications 2006;364:423-34.

11. Bauer A, Kantelhardt JW, Barthel P, et al. Deceleration capacity of heart rate as a predictor of mortality after myocardial infarction: Cohort study. Lancet 2006;367(9523):1674-81.

12. Lewis MJ, Annandale J, D’Silva LA, Davies RE, Reed $\mathrm{Z}$, Lewis KE. Influence of long-term oxygen therapy on cardiac acceleration and deceleration capacity in hypoxic patients with chronic obstructive pulmonary disease. Clin Physiol Funct Imaging 2011;31(4):25865.

13. Campana LM, Owens RL, Clifford GD, Pittman SD, Malhotra A. Phase-rectified signal averaging as a sensitive index of autonomic changes with aging. J Appl Physiol (1985) 2010;108(6):1668-73.

14. Kantelhardt JW, Bauer A, Schumann AY, et al. Phaserectified signal averaging for the detection of quasiperiodicities and the prediction of cardiovascular risk. Chaos 2007;17(1):015112.

15. McNarry MA, Lewis MJ. Interaction between age and aerobic fitness in determining heart rate dynamics. Physiol Meas 2012;33(6):901-14.

16. Casati D, Stampalija T, Ferrazzi E, et al. Maternal cardiac deceleration capacity: A novel insight into maternal autonomic function in pregnancies complicated by hypertensive disorders and intrauterine growth restriction. Eur J Obstet Gynecol Reprod Biol 2016;206:6-11.

17. Borg GA. Perceived exertion: A note on "history" and methods. Med Sci Sports 1973;5(2):90-3.

18. Royal College of Obstetricians and Gynaecologists. Exercise in pregnancy. RCOG Statement No. 4. January 2006. [Available at: http://www.rcog.org. uk/files/rcog-corp/Statement4-14022011.pdf]

19. Speranza G, Verlato G, Albiero A. Autonomic changes during pregnancy: Assessment by spectral heart rate variability analysis. J Electrocardiol 1998;31(2):1019.

20. Kuo CD, Chen GY, Yang MJ, Lo HM, Tsai YS. Biphasic changes in autonomic nervous activity during pregnancy. Br J Anaesth 2000;84(3):323-9.

21. Chamchad D, Horrow JC, Nakhamchik L, Arkoosh VA. Heart rate variability changes during pregnancy: An observational study. Int $J$ Obstet Anesth 2007;16(2):106-9.

22. Stutzman SS, Brown CA, Hains SM, et al. The effects of exercise conditioning in normal and overweight pregnant women on blood pressure and heart rate variability. Biol Res Nurs 2010;12(2):137-48.

23. Paynter C, Meacham C, Ramar C, Gustafson KM, Suminski RR, May LE. Maternal heart rate and heart rate variability during pregnancy and exercise training. FASEB J 2010;24(1 Suppl):618.26.

24. Mone F, McConnell B, Thompson A, et al. Fetal umbilical artery Doppler pulsatility index and childhood neurocognitive outcome at 12 years. BMJ Open 2016;6(6):eoo8916.

25. Graatsma EM, Mulder EJ, Vasak B, et al. Average acceleration and deceleration capacity of fetal 


\section{EDORiUM Journals}

Edorium J Matern Child Health 2019;4:100007M01RC2019.

www.ejmaternalchildhealth.com

heart rate in normal pregnancy and in pregnancies complicated by fetal growth restriction. J Matern Fetal Neonatal Med 2012;25(12):2517-22.

26. Lobmaier S, Huhn E, Pildner von Steinburg S, et al. Phase-rectified signal averaging as a new method for surveillance of growth restricted fetuses. J Matern Fetal Neonatal Med 2012;25(12):2523-8.

27. Stampalija T, Casati D, Monasta L, et al. Brain sparing effect in growth-restricted fetuses is associated with decreased cardiac acceleration and deceleration capacities: A case-control study. BJOG 2016;123(12):1947-54.

28. Stampalija T, Casati D, Montico M, et al. Parameters influence on acceleration and deceleration capacity based on trans-abdominal ECG in early fetal growth restriction at different gestational age epochs. Eur J Obstet Gynecol Reprod Biol 2015;188:104-12.

$* * * * * * * * *$

\section{Acknowledgments}

Dr Carpenter received a NISCHR (Welsh Government National Institute for Social Care and Health Research) $\mathrm{PhD}$ studentship (HS/10/07), and The Cooperative Pharmacy (UK) provided financial support for project consumables.

\section{Author Contributions}

Rhiannon Carpenter - Conception of the work, Design of the work, Acquisition of data, Analysis of data, Interpretation of data, Drafting the work, Revising the work critically for important intellectual content, Final approval of the version to be published, Agree to be accountable for all aspects of the work in ensuring that questions related to the accuracy or integrity of any part of the work are appropriately investigated and resolved
Michael J Lewis - Conception of the work, Design of the work, Acquisition of data, Analysis of data, Interpretation of data, Drafting the work, Revising the work critically for important intellectual content, Final approval of the version to be published, Agree to be accountable for all aspects of the work in ensuring that questions related to the accuracy or integrity of any part of the work are appropriately investigated and resolved

\section{Guarantor of Submission}

The corresponding author is the guarantor of submission.

\section{Source of Support}

None.

\section{Consent Statement}

Written informed consent was obtained from the patient for publication of this article.

\section{Conflict of Interest}

Authors declare no conflict of interest.

\section{Data Availability}

All relevant data are within the paper and its Supporting Information files.

\section{Copyright}

(C) 2019 Rhiannon Carpenter et al. This article is distributed under the terms of Creative Commons Attribution License which permits unrestricted use, distribution and reproduction in any medium provided the original author(s) and original publisher are properly credited. Please see the copyright policy on the journal website for more information.
Access full text article on other devices

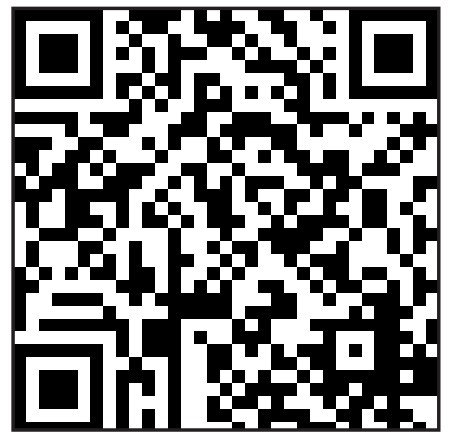

Access PDF of article on other devices

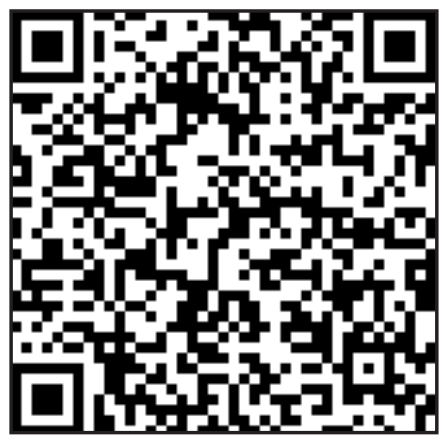




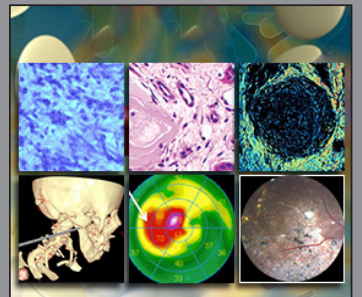

INTERNATIONAL JOURNAL OF CASE REPORTS AND IMAGES
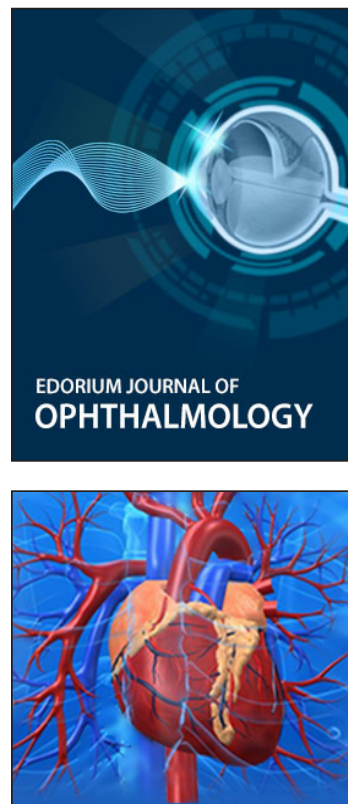

EDORIUM JOURNAL OF

CARDIOTHORACIC AND

VASCULAR SURGERY
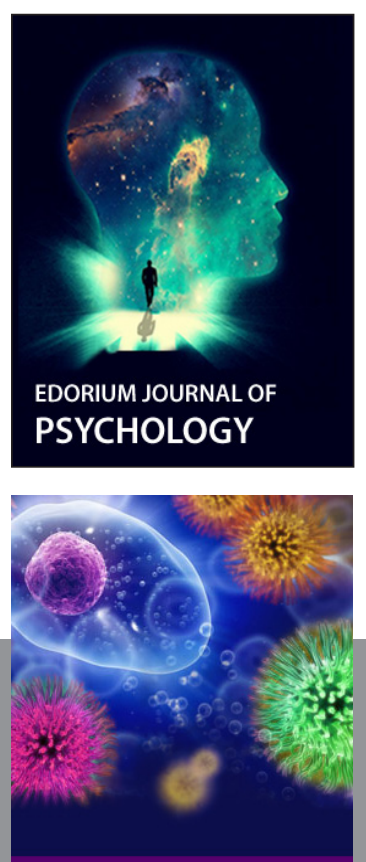

JOURNAL OF CASE REPORTS AND IMAGES IN INFECTIOUS DISEASES
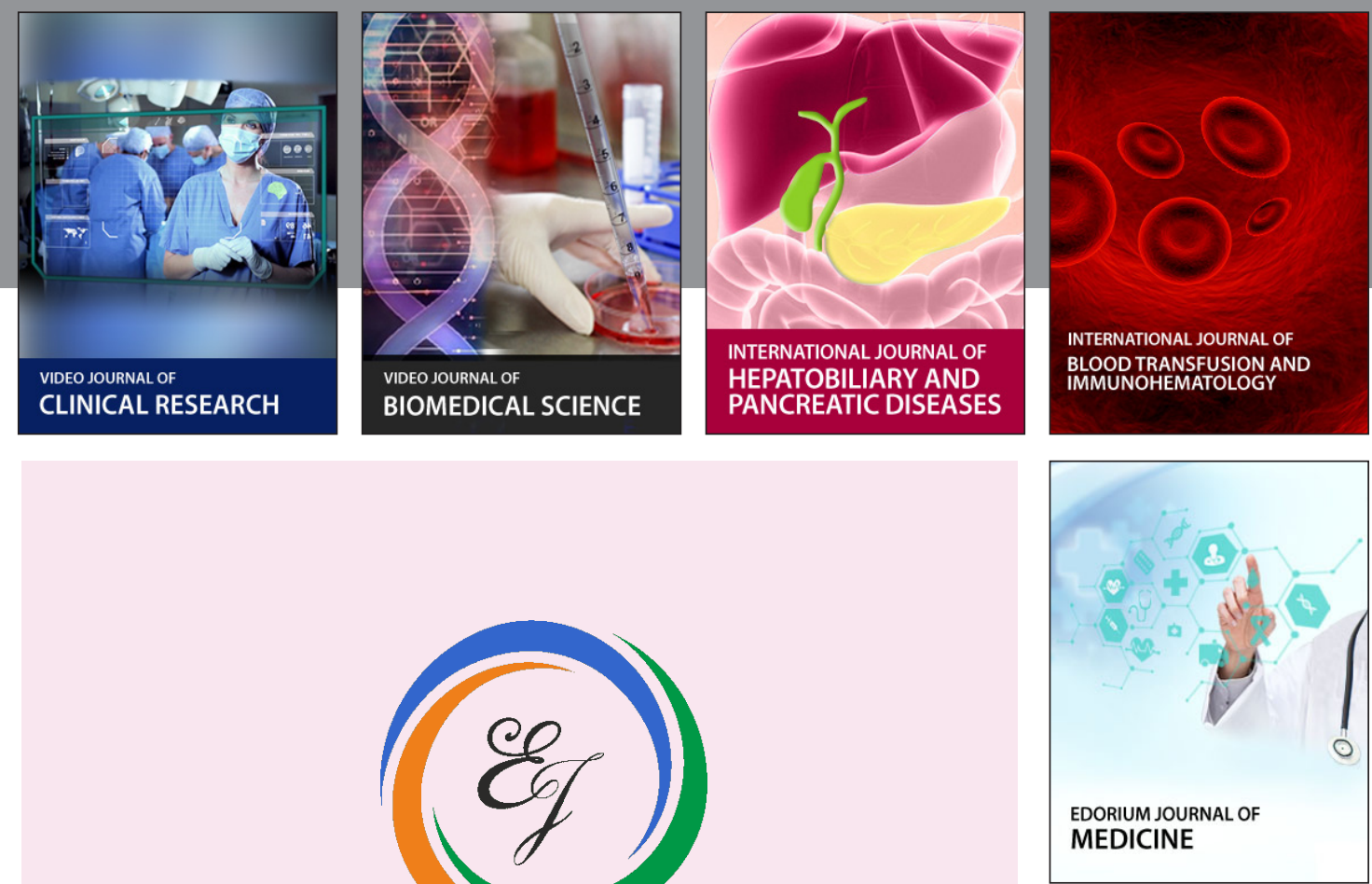

\section{Submit your manuscripts at}

www.edoriumjournals.com
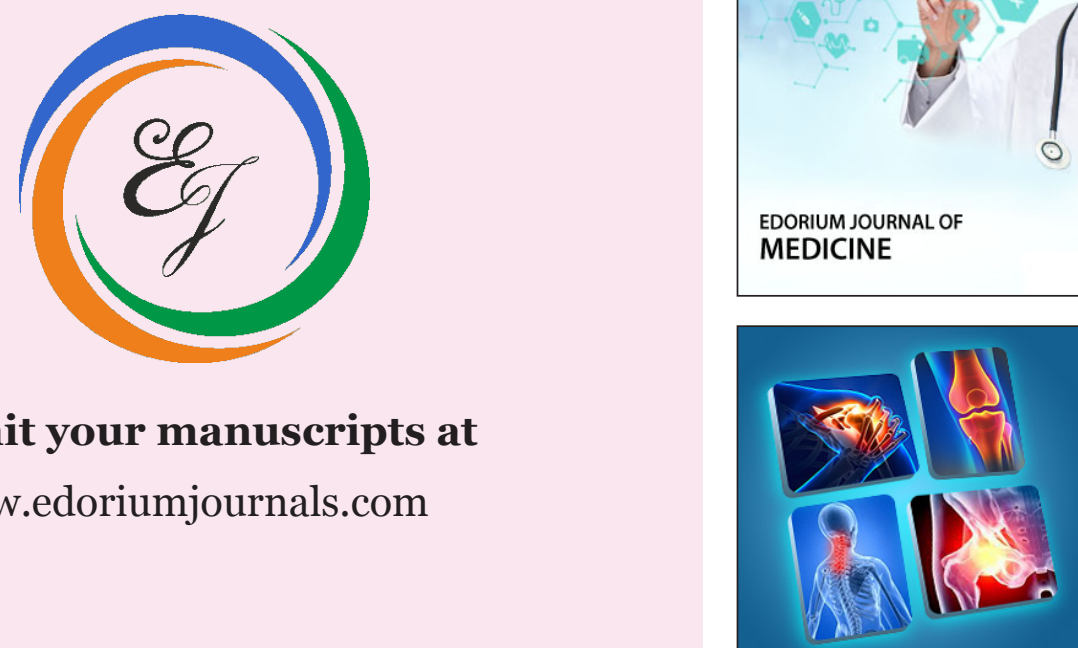

JOURNAL OF CASE REPORTS AND IMAGES IN ORTHOPEDICS AND RHEUMATOLOGY
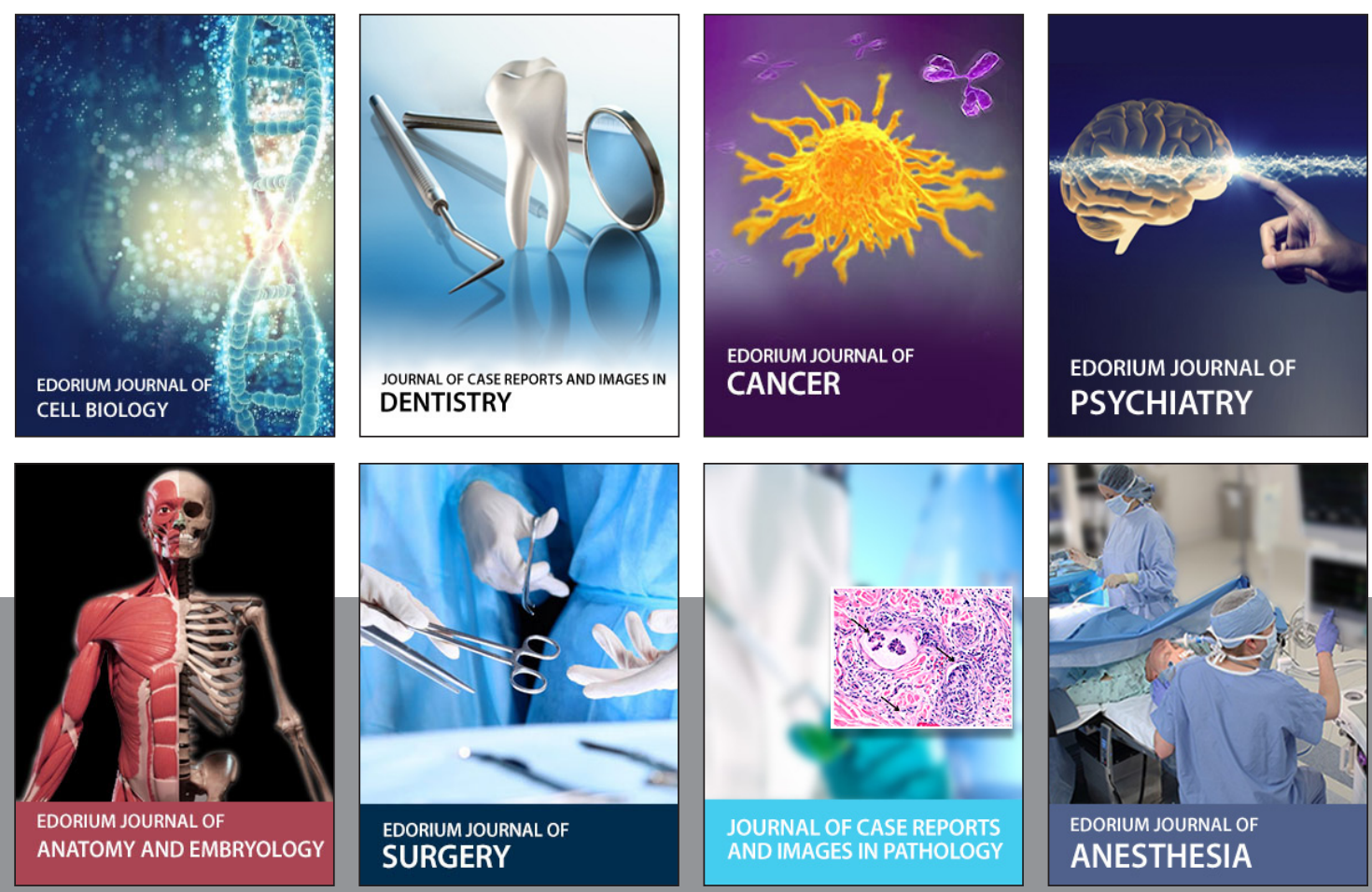